\title{
Aspirin hypersensitivity in Iranian patients with chronic rhinosinusitis and nasal polyposis: prevalence and comorbid factors
}

\author{
Hossein Esmaeilzadeh ${ }^{1 *}$, Mohammad Nabavi ${ }^{2}$, Saba Arshi ${ }^{2}$, Mohammad Hassan Bemanian², Ahmad Bahrami ${ }^{3}$, \\ Morteza Fallahpour ${ }^{3}$, Negar Mortazavi ${ }^{4}$, Nima Rezaei ${ }^{5}$
}

From 6th Drug Hypersensitivity Meeting (DHM 6)

Bern, Switzerland. 9-12 April 2014

\section{Background}

Aspirin (ASA) hypersensitivity is frequent in patients with chronic rhinosinusitis and nasal polyps (CRSwNP), which is called aspirin exacerbated respiratory disease (AERD). However, there are few studies on evaluating the prevalence of ASA hypersensitivity in patients with nasal polyps (NPs), using the oral aspirin challenge test. This study was designed to determine the frequency of ASA hypersensitivity and factors associated with ASA hypersensitivity in patients with CRSwNP.

\section{Methods}

Eighty Iranian patients (43 women and 37 men) with CRSwNP were enrolled in this study. Extension of NPs was evaluated by endoscopic examination. A single day, oral aspirin challenge (OAC) was used to detect ASA hypersensitivity. Atopic evaluation was performed, using skin prick test, nasal smear, blood eosinophil count, and serum total IgE.

\section{Results}

OAC was performed in all patients (mean age: $38.9 \pm$ 10.7 years). OAC resulted positive in 39 patients (48.8\%); among them 14 (35.8\%) had history of ASA hypersensitivity, while 2 patients $(12.5 \%)$ with positive history were negative through OAC. Concomitant asthma, pervious polyp surgery, high polyp score and ASA hypersensitivity history were all associated with positive OAC $(\mathrm{p}<0.05)$. Presence of AERD was not associated with age, stage of asthma, blood eosinophilia, nasal smear eosinophilia and atopy.

${ }^{1}$ Tehran University of Medical Science, Iran

Full list of author information is available at the end of the article

\section{Conclusion}

ASA hypersensitivity is quite common in patients with CRSwNP. Patients at risk for AERD require evaluation for the presence of ASA hypersensitivity with ASA provocation challenge test to confirm the diagnosis.

\section{Authors' details}

${ }^{1}$ Tehran University of Medical Science, Iran. ${ }^{2}$ Iran University of Medical Science, Allergy and Clinical Immunology, Iran. ${ }^{3}$ Tehran University of Medical Science, Allergy and Clinical Immunology, Iran. ${ }^{4}$ Shahid Beheshti Medical University, Clinical Pharmecy Department, Iran. ${ }^{5}$ Tehran University of Medical Science, Molecular Immunology Research Center, Iran.

Published: 18 July 2014

doi:10.1186/2045-7022-4-S3-P22

Cite this article as: Esmaeilzadeh et al: Aspirin hypersensitivity in Iranian patients with chronic rhinosinusitis and nasal polyposis: prevalence and comorbid factors. Clinical and Translational Allergy 2014 4(Suppl 3):P22.

\section{Submit your next manuscript to BioMed Central and take full advantage of: \\ - Convenient online submission \\ - Thorough peer review \\ - No space constraints or color figure charges \\ - Immediate publication on acceptance \\ - Inclusion in PubMed, CAS, Scopus and Google Scholar \\ - Research which is freely available for redistribution

